\title{
A simple and novel marking method for correctly identifying the precutting direction to achieve safe and efficacious precut sphincterotomy (with video) $\square$
}

다(1)우우

Kazumasa Nagai, Akio Katanuma, Kuniyuki Takahashi, Kei Yane, Toshifumi Kin, Hiroyuki Maguchi

\author{
Authors \\ Institution \\ Center for Gastroenterology, Teine-Keijinkai Hospital, \\ Sapporo, Japan \\ submitted 22.11.2017 \\ accepted after revision 9.5.2018 \\ Bibliography \\ DOI https://doi.org/10.1055/a-0752-9755 | \\ Endoscopy International Open 2019; 07: E3-E8 \\ (c) Georg Thieme Verlag KG Stuttgart · New York \\ ISSN 2364-3722 \\ Corresponding author \\ Kazumasa Nagai, MD, Center for Gastroenterology, Teine \\ Keijinkai Hospital, 1-40, 1-jo 12-chome, Maeda, Teine-ku, \\ Sapporo 006-8555, Japan \\ Phone: +81-11-681-8111 \\ Fax: $+81-11-685-2967$ \\ kazu4439@gmail.com
}

\section{ABSTRACT}

Background and study aims Failure to recognize the right direction and precise incision length during precutting has been reported. To address these concerns, we developed a marking method that places a marking on the cutting endpoint before starting precutting. This preliminary study aimed to assess the effectiveness and safety of precut sphincterotomy using our new marking method.

Patients and methods Between April 2015 and May 2017, 21 patients from our tertiary referral center were included in this study. Precut sphincterotomy using our marking method was employed for difficult common bile duct cannulation cases. Before starting precutting, a marking was placed slightly before the upper margin of the bulge of the papilla in the 11- to 12-o'clock direction as a cutting endpoint by cauterization with a needle knife.

Results Technical success was obtained in all 21 procedures. There were no post-endoscopic retrograde cholangiopancreatography (ERCP) complications except for one mild case of post-ERCP pancreatitis.

Conclusion Our new marking method before precutting enabled precise incision and quick bile duct cannulation without causing severe complications.

\section{Introduction}

Endoscopic retrograde cholangiopancreatography (ERCP) is commonly used to diagnose and treat pancreatic and biliary disorders. Selective biliary cannulation during ERCP is required for all therapeutic biliary procedures and is achieved in approximately $90 \%$ of cases by standard cannulation techniques [1]. Failed biliary cannulation using standard techniques occurs in up to $10 \%$ of all ERCPs [2]. Precut sphincterotomy is used to facilitate common bile duct (CBD) cannulation by cutting the papilla before guidewire passage into the CBD [3]. However, this technique is usually associated with higher rates of intraoperative and postoperative complications than standard methods, and reserved for experts $[4,5]$. In fact, there have been cases of failure to recognize the right direction and the precise incision length during precutting because of anatomical abnormalities, such as diverticulum, tumor invasion, and duodenal mal- formation. Improper precutting direction may cause perforation or bleeding and difficulty with bile duct recognition.

To address these concerns, we developed a marking method that places a marking slightly before the upper margin of the bulge of the papilla in the 11- to 12-o'clock direction as a cutting endpoint before starting precutting. To our knowledge, this preliminary study describes the first case series of this new marking method before precut sphincterotomy for difficult cannulation cases.

\section{Patients and methods}

\section{Patients}

A flow diagram of this study is shown in $>$ Fig. 1. Between April 2015 and May 2017, a total of 1,865 consecutive ERCPs were performed for primary biliary indications. After excluding patients with previous biliary interventions, Billroth II operation, 


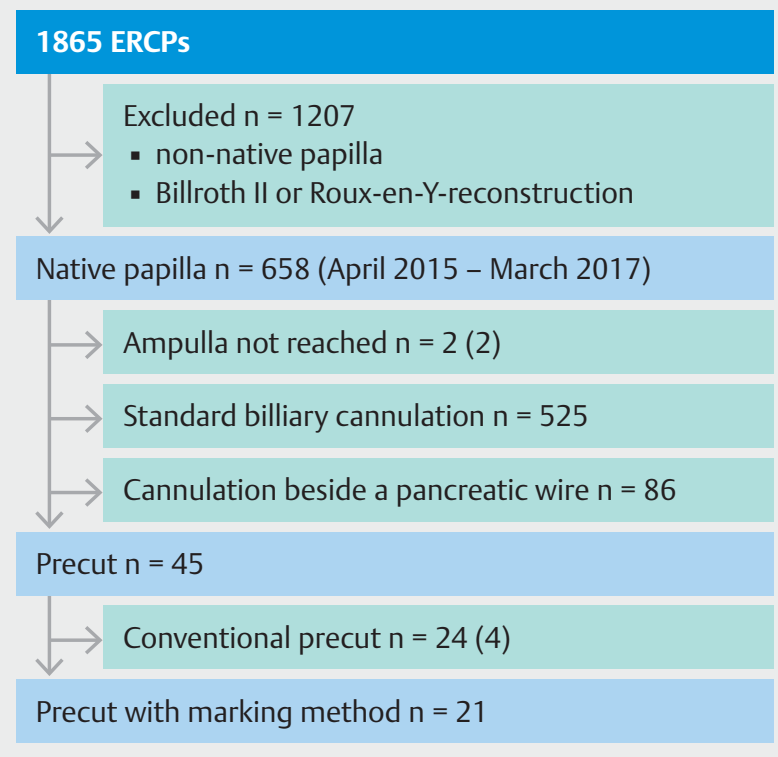

Fig. 1 Flow diagram of the study. The number of patients in whom biliary cannulation failed are indicated in parentheses.

or Roux-en-Y reconstruction, 658 native papillae ERCPs were performed. Of these 658 cases, the ampulla was reached in 656 cases, and successful biliary cannulation was achieved using the standard cannulation technique in 525 cases, with the technique of cannulation performed beside a pancreatic wire in 86 cases. In the remaining 45 cases, precut sphincterotomy was performed. Of these 45 cases, 24 cases in which precut was performed using the conventional method were excluded in this study. Finally, 21 patients ( 11 men, 10 women) who underwent precut sphincterotomy using our marking method in our hospital were included in this study.

\section{Methods}

All endoscopic procedures were performed with patients under moderate sedation using intravenous (IV) diazepam or midazolam. All patients received intravenous drip infusions of pethidine hydrochloride during ERCP.

Antibiotic treatment consisted of cefotiam hydrochloride $(1 \mathrm{~g})$ IV drip infusion once on the test day and twice on the following day. ERCPs were performed using a side-viewing therapeutic duodenoscope (TJF-260V: Olympus Medical Systems, Tokyo, Japan) with the patient in the prone position using carbon dioxide insufflation. An electrosurgical generator with a controlled cutting system (ESG-100: Olympus Medical Systems, Tokyo, Japan) was used for marking and precutting with the slow mode of pulse cut at $60 \mathrm{~W}$.

Selective CBD cannulation was first attempted using sphincterotomes (TRUEtome: Boston Scientific, Natick, Massachusetts, United States; CleverCut: Olympus Medical Systems, Tokyo, Japan) or a catheter (ERCP catheter: MTW Endoscopie Co., Ltd., Wesel, Germany) with the aid of a 0.025 -inch guidewire (VisiGlide 2: Olympus Medical Systems, Tokyo, Japan). Cannulation beside a pancreatic wire was performed if the first attempt

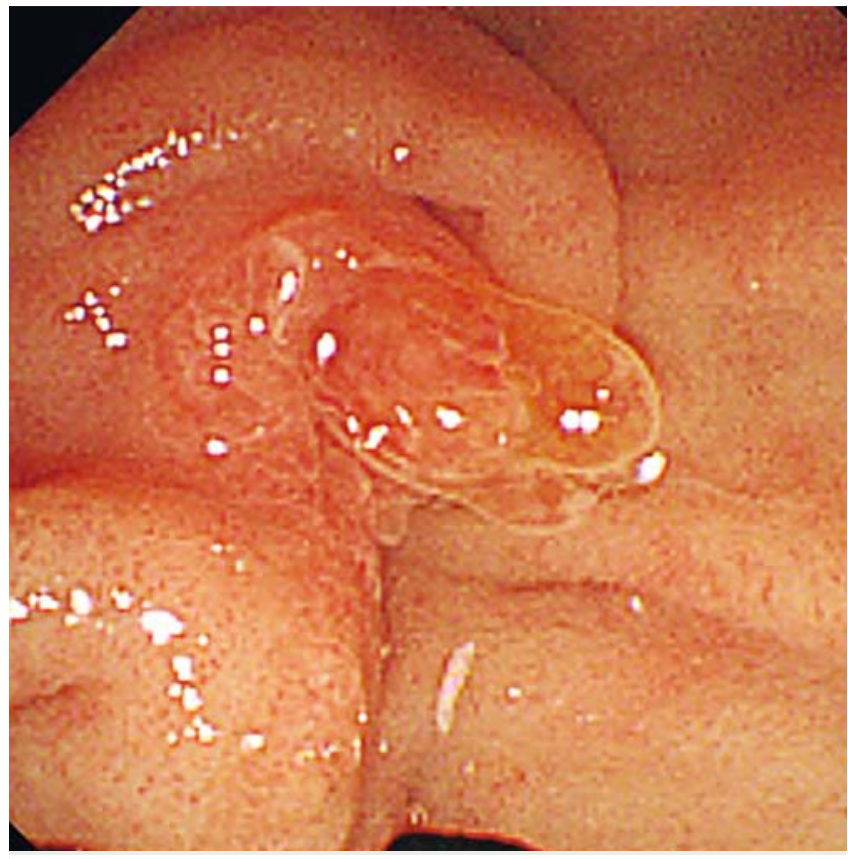

Fig. 2 Endoscopic image showing the duodenal papilla of a case.

failed. Choice and sequence of biliary devices and cannulation methods were at the endoscopist's discretion. Precut sphincterotomy using our marking method was used if access failed with the cannulation equipment.

The first CBD cannulation attempts were performed by the attending staff physicians and trainees, whereas the other cannulations including precut sphincterotomy requiring advanced techniques were performed by four attending staff physicians with at least 5 years of experience in therapeutic biliary endoscopy.

Technical success was defined as achieving biliary cannulation after precutting. Medical records and video recordings of the procedures were retrospectively reviewed in all cases. This is a preliminary study aimed at demonstrating the feasibility of this marking method.

\section{Precut sphincterotomy using our marking method}

Before starting precutting, a marking was placed slightly before the upper margin of the bulge of the papilla in the 11- to 12o'clock direction as a cutting endpoint by cauterization with a needle knife (Needle knife V: Olympus Medical Systems, Tokyo, Japan) ( $\vee$ Fig. 2, $\triangleright$ Fig.3). Subsequently, the needle knife was placed at the papillary orifice and an incision was made towards the marking. After reaching the marking, an incision was added to splay open the ampulla in layers to expose the sphincter muscle and the bile duct orifice ( $\triangleright$ Fig.4). When the appropriate incision was obtained, CBD cannulation was attempted using the catheter with the aid of a guidewire. If the cannulation failed, the precutting was extended and cannulation was reattempted. Once CBD cannulation was achieved, the incision was extended using the sphincterotome in all cases. 


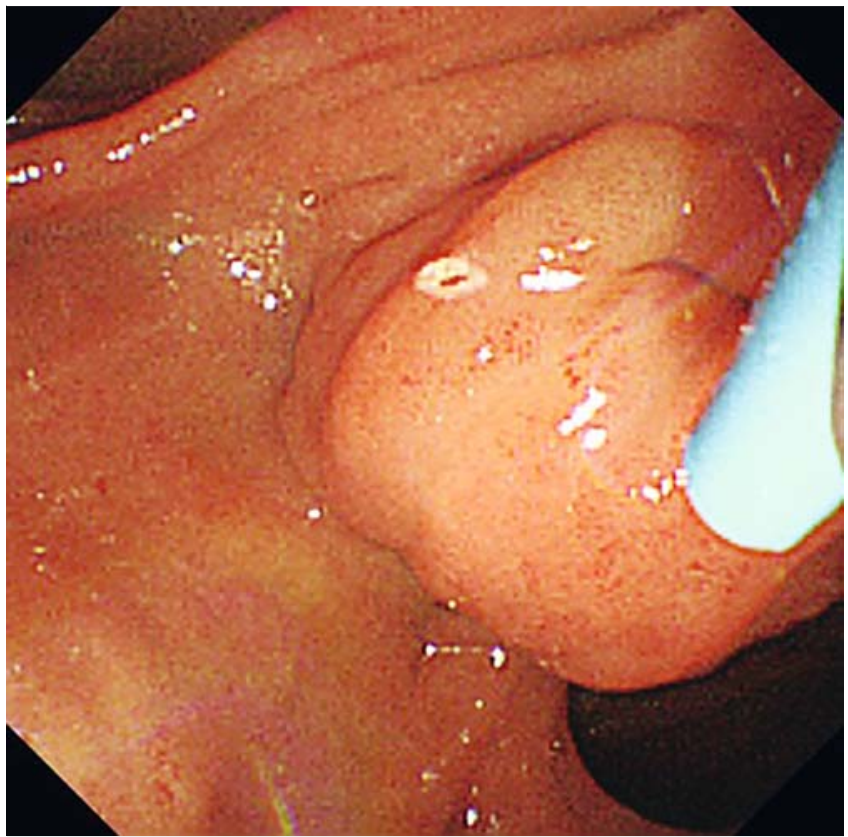

- Fig. 3 Endoscopic image showing a marking placed slightly before the upper margin of the bulge of the papilla in the 11- to 12-o'clock direction as a cutting endpoint by cauterization with a needle knife.

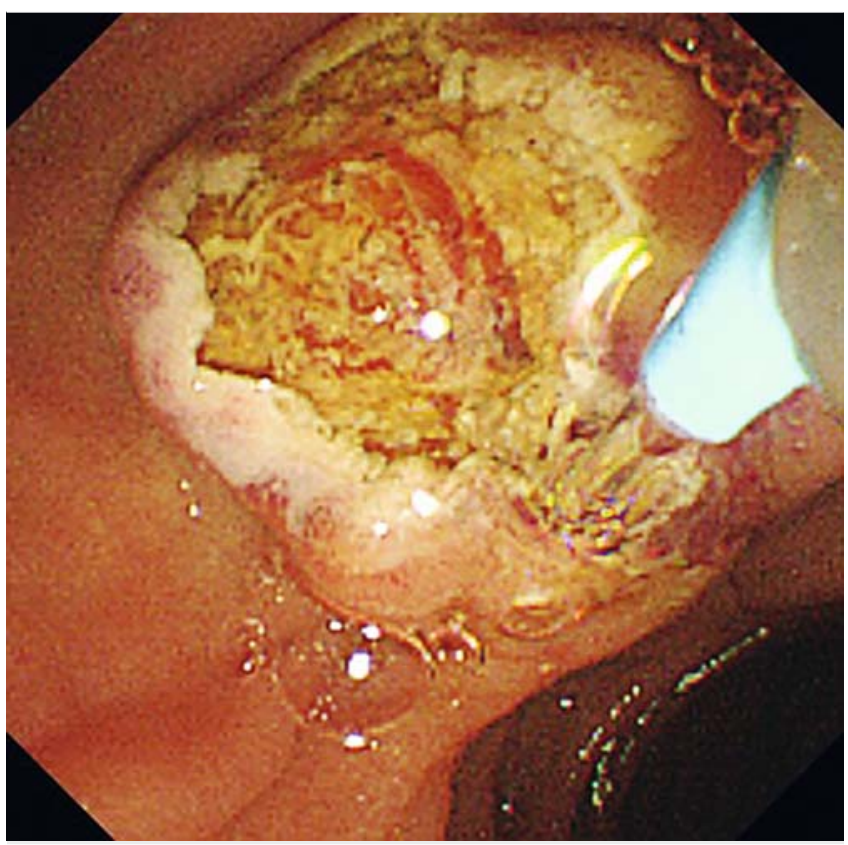

Fig. 4 Endoscopic image showing exposure of the sphincter muscle of the duodenal papilla after precutting.

\section{Results}

Precut sphincterotomy using our marking method was performed in 21 patients ( 11 men, 10 women; median age: 78 years [range $43-87$ years]). All patients had an Eastern Cooperation Oncology Group performance status of 0 or 1 . Baseline characteristics are summarized in $>$ Table 1.

A pancreatic stent (Wilson-Cook Medical Inc., WinstonSalem, NC) was placed in three cases of CBD stone in place of the pancreatic wire, and precutting was performed using the pancreatic stent as a guide. All pancreatic stents were removed passively during the stone extraction procedure. Median time from the first cannulation attempt to starting precutting was 22 minutes (range 14-39 minutes). Median procedural time was 59 minutes (range 38-89 minutes). The pancreatic duct was injected at least once in all cases.

Successful biliary cannulation after precut sphincterotomy was achieved in all cases using our marking method. Median time to achieve biliary cannulation after precutting was 3 minutes (range 0.3-36 minutes). All patients except one had no complications including bleeding, perforation, or death. One patient had post-ERCP pancreatitis (PEP), but recovered immediately with conservative treatment. The procedures are summarized in $>$ Table 2 .

\section{Discussion}

At present, many cases of failed conventional cannulation have become successful with use of the double guidewire technique. However, the fact remains that such cannulation techniques failed in some cases, as shown in our study diagram. According to a previous review [1], the precut technique was performed in $4 \%$ to $38 \%$ of all cannulation cases. Compared with the double guide technique, the precut technique has advantages of reducing not only medical expense from use of two guidewires but also risk of PEP, making the precut technique still indispensable.

Precut sphincterotomy is a frequently used modality that significantly improves successful cannulation rates; however, it is often considered a "dangerous" and "complicated" technique reserved for "experts" [5].

The precise incision direction is one of the most important factors for successful precut. Although the bile duct location in the ampulla of Vater has not yet been elucidated, experts have indicated that the precise direction would be the 11- to 12-o'clock direction of the ampulla of Vater in terms of EST [6]. Practically, various morphologies exist (e. g., diverticulum). Therefore, a method of determining the orientation by marking after careful observation around the papilla would be considered important and effective.

The orientation and upper limit of the incision are considered important technical factors for a safe and effective precut. However, once precut is started, the orientation and endpoint of the incision are difficult to recognize because the bulge of the papilla is collapsed by precutting. Thus, we thought that the direction and endpoint of the incision should be defined before starting the incision. 
- Table1 Baseline characteristics of the patients.

\begin{tabular}{|l|l|}
\hline Age, y, median (range) & $72(43-87)$ \\
\hline Sex, male/female, no. & $11 / 10$ \\
\hline Indications, no. & $9(43 \%)$ \\
\hline - Stone & $12(57 \%)$ \\
\hline - Malignant jaundice & \\
\hline Papillary morphology & $3 / 18$ \\
\hline - Flat/protruded & \\
\hline Anatomical abnormality & $3(14 \%)$ \\
\hline - Peripapillary diverticulum & $2(10 \%)$ \\
\hline - Stricture of duodenum & $2(10 \%)$ \\
\hline - Tumor invasion to papilla & \\
\hline
\end{tabular}

- Table 2 Characteristics of the procedures.

Technical success rate

$100 \%(21 / 21)$

Additional endoscopic therapy

- Sphincterotomy 19

- NBT/Biliary stent

- CBD sweeping

5

Time from the first attempt of cannulation to the start of precutting* (minutes)

$22(14-39)$

Time to achieve CBD cannulation after precutting* $\quad 3(0.3-36)$ (minutes)

Total procedural time* (minutes) $59(38-89)$

Complication rate $5 \%(1 / 21)$

CBD, common bile duct; NBT, nasobiliary tube * Median

Some of the most important precut sphincterotomy complications are bleeding and perforation. According to previous reports, the post-procedure bleeding rate ranged from $0 \%$ to $20 \%$, and the perforation rate from $0 \%$ to $4 \%$ [7 - 10]. Mirjalili and Stringer suggested that arterial bleeding may be reduced by performing sphincterotomy in the 10- to 11-o'clock position because of the small number of papillary arteries in the area [11]. Park et al. mentioned that the endoscopic landmark indicating the intramural segment of the bile duct is the papillary roof of the ampulla of Vater. Thus, they suggested that the incision should not be extended through the proximal horizontal fold to avoid perforation [12]. Our marking method can potentially reduce risk of bleeding and perforation, because the right direction and the upper limit of the incision are predefined by placing a marking. PEP is also an important complication of precut sphincterotomy, but it is not yet clear whether this marking method contributes to PEP prophylaxis.

Another important obstacle of precut sphincterotomy is the sustained failure of bile duct cannulation even after precutting by experts [13]. An edematous and shaggy ampulla of Vater induced by precutting may be related to unsuccessful bile duct cannulation [14]. Chiu et al. reported that mean time to achieve biliary cannulation after precut sphincterotomy was 9 minutes and 4 seconds [15]. Compared with this, median time to achieve biliary cannulation after precut sphincterotomy in the current study was 3 minutes. Making an incision in the right direction may have contributed to exposing the sphincter muscle and eventually the bile duct orifice.

To verify the validity of our method, we examined 24 cases in which biliary cannulation was attempted using the conventional precut technique during the study period. These 24 cases were treated by two other experts with more than 20 years of experience who did not participate in this study. The successful cannulation rate was $83 \%(20 / 24)$ and the complication rate was $21 \%$ (5/24). Complications included three cases of mild PEP and two cases of minor perforation, all of which were improved by conservative treatment. Details of these cases are shown in the Supplementary Table. From these results, we can assume that our method would be helpful.

In this study, a pancreatic stent was placed to reduce risk of PEP in three CBD stone cases because the pancreatic duct was cannulated several times unintentionally. Although placement of the pancreatic stent occasionally made it more difficult to perform precut, precutting was achieved in these three cases. Complications including PEP were not observed, although the pancreatic stent was removed passively during the procedure.

There are several concerns regarding our marking method. First, there is a risk that the marking itself will cause bleeding or perforation, although this may be avoided by carefully marking the right spot. This was evidenced by absence of bleeding or perforation in the current study. Another concern with precut sphincterotomy is perforation caused by deep incision. This can occur even if the incision is made in the right direction. Future improvements to avoid this are needed.

Second, there were only a few cases that showed papillary morphology owing to tumor invasion or diverticulum. We could not clarify in this study whether our technique would be effective for papillary morphology cases. To date, randomized controlled trials or prospective cohort studies comparing the success and safety of precut techniques in elation to papillary morphology have not been conducted [6]. Further examinations, therefore, are necessary.

Third, the depth of cutting cannot be strictly guided with use of our marking method. However, this marking method makes it easy to precisely incise towards the correct direction, which may avoid unnecessary deeper incision. This advantage may possibly reduce complications such as bleeding and perforation.

Our work has limitations in terms of being a retrospective study, the small number of patients, and the lack of comparisons. Also, the involved physicians were expert endoscopists from a large-volume center, which may be related to the high procedural success rate without complications. 


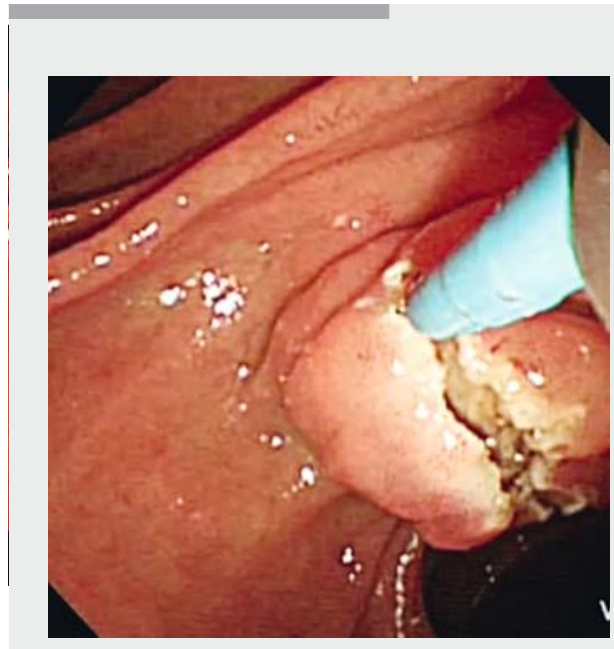

Video A marking was placed slightly before the upper margin of the bulge of the papilla in the 11 -to 12 -o'clock direction as a cutting endpoint by cauterization with a needle knife before precutting. Subsequently, the needle knife was placed at the papillary orifice and an incision was made towards the marking. After reaching the marking, an incision was added to splay open the ampulla in layers to expose the sphincter muscle. When the appropriate incision was obtained, CBD cannulation was attempted using the catheter with the aid of a guidewire.

\section{Conclusion}

In conclusion, the current case series showed that our novel marking method before precutting enables precise incision and quick bile duct cannulation without causing severe complications. Further prospective studies, in which trainees are enrolled, should be conducted to compare clinical outcomes and effectiveness of our new marking method with those of conventional precut sphincterotomy.

\section{Acknowledgements}

We thank Dr. Edward Barroga (http://orcid.org/0000-00028920-2607) for reviewing and editing the manuscript.

\section{Competing interests}

None

\section{References}

[1] Freeman ML, Guda NM. ERCP cannulation: a review of reported techniques. Gastrointest Endosc 2005; 61: 112-125

[2] Bailey AA, Bourke M], Williams SJ et al. A prospective randomized trial of cannulation technique in ERCP: effects on technical success and post-ERCP pancreatitis. Endoscopy 2008; 40: 296 -301

[3] Siegel JH. Precut papillotomy: a method to improve success of ERCP and papillotomy. Endoscopy 1980; 12: $130-133$

[4] Masci E, Mariani A, Curioni S et al. Risk factors for pancreatitis following endoscopic retrograde cholangiopancreatography: a meta-analysis. Endoscopy 2003; 35: 830-834

[5] Cotton PB. Precut sphincterotomy: a risky technique for the experts only. Gastrointest Endosc 1989; 35: 578 - 579

[6] Testoni PA, Mariani A, Willams EJ et al. Papillary cannulation and sphincterotomy techniques at ERCP: European Society of Gastrointestinal Endoscopy (ESGE) Clinical Guideline. Endoscopy 2016; 48: $657-683$

[7] Shakoor T, Geenen JE. Pre-cut papillotomy. Gastrointest Endosc 1992; 38: $623-627$

[8] Kasmin FE, Cohen D, Batra S et al. Needle-knife sphincterotomy in a tertiary referral center: efficacy and complications. Gastrointest Endosc 1996; 44: $48-53$

[9] Binmoeller KF, Seifert H, Gerke H et al. Papillary roof incision using the Erlangen-type pre-cut papillotome to achieve selective bile duct cannulation. Gastrointest Endosc 1996; 44: 689-695

[10] Akashi R, Kiyozumi T, Jinnouchi K et al. Pancreatic sphincter precutting to gain selective access to the common bile duct: a series of 172 patients. Endoscopy 2004; 36: 405-410

[11] Mirjalili SA, Stringer MD. The arterial supply of the major duodenal papilla and its relevance to endoscopic sphincterotomy. Endoscopy 2011; 43: $307-311$

[12] Park DH, Park SH, Kim HJ et al. A novel method for estimating the safe margin and the adequate direction of endoscopic biliary sphincterotomy in choledocholithiasis with complications (with videos). Gastrointest Endosc 2006; 64: 979-983

[13] Sriram PV, Rao GV, Nageshwar Reddy D. The precut: when, where and how? A review. Endoscopy 2003; 35: S24-S30

[14] Park SH, Park do H, Lee TH et al. Feasibility of the mucosa-tracking technique in precut papillotomy with the iso-tome as an alternative to the needle-knife technique. Gut Liver 2010; 4: 76-83

[15] Chiu PWY, Ng EKW, Teoh AYB et al. Precut sphincterotomy using insulated angulotome. Endoscopy 2010; 42: 338-341 
- Supplementary Table Characteristics of 24 patients who underwent conventional precut.

\begin{tabular}{|l|l|}
\hline Age, y, median (range) & $72(45-97)$ \\
\hline Sex, male/female, no. & $11 / 13$ \\
\hline Indications, no & \\
\hline - Stone & $11(46 \%)$ \\
\hline - Malignant jaundice & $11(46 \%)$ \\
\hline - Sphincter dysfunction & $2(8 \%)$ \\
\hline Papillary morphology & \\
\hline - Flat/protruded & $4 / 20$ \\
\hline Technical success rate & $83 \%(20 / 24)$ \\
\hline Complication rate & $21 \%(5 / 24)$ \\
\hline
\end{tabular}

